\title{
Atypical BSE: Current Knowledge and Knowledge Gaps
}

\author{
Sandor Dudas and Stefanie Czub \\ Canadian BSE Reference Laboratory, Canadian Food Inspection Agency Lethbridge Laboratory, Lethbridge, \\ Canada
}

Atypical BSE is an invariably fatal neurologic disease of cattle caused by misfolded prion proteins with different conformations than those associated with classical BSE. Evidence suggests that these atypical BSE types are sporadic or genetic prion diseases of cattle and the relevance of these diseases, as far as natural transmissibility, is still unknown. Different misfolded prion protein conformations also result in unique biochemical characteristics. This raised concerns about detection of atypical BSE on rapid test platforms designed and validated for classical BSE prions. Despite the differences in the misfolded prion protein characteristics, studies have shown that the tests also work well for detecting the known types of atypical BSE. A new question that has recently emerged is related to the possibility of additional forms of atypical BSE. Initially reactive bovine brain samples on certain rapid surveillance tests have sparked debate about the true BSE status of these samples. Work is currently underway to determine if these samples are infectious and if they eventually result in neurologic disease in cattle. Results of these studies could impact future BSE diagnostic testing programs as well as human and animal health policies.

Key words: atypical BSE, bovine spongiform encephalopathy, neurologic disease, prion, PrP

\section{Atypical BSE}

Bovine spongiform encephalopathy (BSE) is a prion disease of cattle that is invariably fatal and zoonotic. Three type of BSE have been detected in a number of countries around the world. Classical BSE is the most common types of BSE and the cause of the BSE epidemic in the United Kingdom $^{1)}$. In 2004, two additional types of BSE were identified mostly in older animals ${ }^{2,3)}$ and were named according to the electrophoretic migration of their protease resistant prion protein or $\mathrm{PrP}^{\mathrm{RES}}$. High or $\mathrm{H}$ type $\mathrm{BSE} \operatorname{PrP}^{\mathrm{RES}}$ is slightly larger, migrates slower and is detected in a position higher than classical BSE, while low or L type BSE PrP ${ }^{R E S}$ is smaller, migrates faster and is detected in a lower position than classical BSE during electrophoresis. Along with these differences in size, $\mathrm{H}$ and $\mathrm{L}$ type atypical BSE also have different biochemical and transmission characteristics, PrPRES distribution and pose different challenges for detection and diagnosis.

\section{Origin of Atypical BSE}

It is well established that classical BSE is transmitted into cattle via contaminated feed or experimental exposure. In the United Kingdom and other countries with a classical BSE, infection can be traced back to the use of BSE contaminated feed supplements ${ }^{4}$. This is, in contrast, not the case with atypical BSE. Most atypical BSE cases have been detected in older cattle and cannot be linked to a common infectious source ${ }^{5)}$. This has led to the concept, that atypical

Received: 9 December 2016; Accepted: 26 December 2016; Published online: 8 February 2017

Corresponding author: Stefanie Czub, Canadian Food Inspection Agency Lethbridge Laboratory, Lethbridge, Alberta, Canada, T1 J $3 Z 4$ (stefanie.czub@inspection.gc.ca)

The contents of this article reflect solely the view of the author(s).

Conflict of interest statement: The authors had no conflicts of interest to declare in this article.

This paper was presented at the Animal Prion Diseases Workshop "Updated Diagnosis and Epidemiology of Animal Prion Diseases for Food Safety and Security" supported by the OECD Co-operative Research Programme. (See "Food Safety" Vol.4 (2016), No.4, 103-4.)

Abbreviations: BSE: Bovine Spongiform Encephalopathy; $\operatorname{PrP}^{\mathrm{RES}}$ : protease resistant prion protein 
BSE may be a sporadic disease in cattle, resulting when the protein folding/misfolding homeostasis can no longer be maintained by protein quality control mechanisms ${ }^{6,7)}$. The sporadic nature of atypical BSE may also be supported by the fact that the incidence rate has not been affected by the implementation of policies to eliminate the transmission source of classical $\mathrm{BSE}^{5}$.

More recently, results suggest that atypical BSE can convert to classical BSE when passaged through experimental animals ${ }^{8,9)}$. If this is possible in mice, it is plausible that this could happen in domestic livestock as well. Rendered material of a cow with a sporadic protein misfolding disease fed into sheep could have been the starting point of the classical BSE epidemic-when fed back into cattle. Dr. Stefanie Czub at the National BSE Reference Laboratory in Alberta, Canada is testing this theory in a current study. Sheep have been challenged with $\mathrm{L}$ and $\mathrm{H}$ type atypical BSE; and the research group is awaiting clinical disease to characterize the biochemical and molecular properties and to type the disease (personal communication, Dr. S. Czub).

Despite genetic causes having been ruled out in most BSE cases, one potentially causative genetic polymorphism has been detected in the prion gene of an $\mathrm{H}$ type atypical BSE case in the United States ${ }^{10}$. In this animal an amino acid change from glutamic acid to lysine at position 211 of the prion protein $(\mathrm{E} 211 \mathrm{~K})$ was detected. This same mutation has also been identified in humans with an inherited form of Creutzfeldt-Jakob disease ${ }^{11)}$. To date this is the only documented case of a bovine prion disease with a genetic mutation in the prion protein open reading frame. Recently, cattle carrying the E211 K mutation and wildtype cattle were challenged intra-cranially with classical BSE or H type BSE from the original E211 K H type BSE animal. E211 K cattle challenged with E211 K H type BSE homogenate had a much shorter incubation time than wildtype cattle challenged with the same inoculum, but an E211 K animal challenged with classical BSE had the same incubation period as a wildtype animal ${ }^{12)}$. The same research group is monitoring a number of unchallenged E211 K animals to determine if inherited atypical BSE will develop. With the increased accessibility to whole genome sequencing, it would be beneficial to explore the genomes of atypical BSE animals to determine if other genetic factors may contribute to the diseases.

\section{Biochemical Characteristics of PrPSC}

Disease associated prion proteins or $\mathrm{PrP}^{\mathrm{SC}}$ acquire properties resulting in a unique, degradation resistant pathogen ${ }^{13)}$. When an animal or human becomes infected with a prion, the cellular prion protein or $\mathrm{PrP}^{\mathrm{C}}$ undergoes a change in its secondary structure. The once primarily alpha helical, normal functioning protein is refolded into a more beta sheet rich protein ${ }^{14)}$. This change makes the protein resistant to degradation, prone to aggregation and the misfolded protein is believed to be the infectious agent responsible for prion disease transmission. $\mathrm{PrP}^{\mathrm{SC}}$ is believed to act on $\mathrm{PrP}^{\mathrm{C}}$ inducing more misfolding into $\mathrm{PrP}^{\mathrm{SC}}$. As this process progresses in the central nervous system, $\mathrm{PrP}^{\mathrm{SC}}$ aggregates and synaptic dysfunction and neurodegeneration occurs. The cause of neurodegeneration is still not conclusively deciphered, but it has been demonstrated that the presence of $\mathrm{PrP}^{\mathrm{C}}$ and its conversion to $\mathrm{PrP}^{\mathrm{SC}}$ is necessary for neurodegeneration ${ }^{15}$.

In BSE, the misfolded prion protein can take on one of three misfolded conformations, namely $\mathrm{C}, \mathrm{H}$ or L type BSE. Classical or C type BSE is used as the standard to evaluate the atypical types. $\mathrm{C}$ type BSE prions are extremely resistant to degradation by protease digestion, even under stringent conditions. In contrast, $\mathrm{H}$ and $\mathrm{L}$ type atypical BSE prions are less resistant and can be degraded by stringent proteinase $\mathrm{K}$ digestion ${ }^{16)}$.

The protease resistant portion of the BSE associated prion protein, also known as $\mathrm{PrP}^{\mathrm{RES}}$, separates into three glycoforms when run on a SDS-polyacrylamide gel. Each glycoform has a characteristic molecular weight and quantity depending on the type of BSE, and glyco-form ratios and molecular weights are used to type BSE. Classical BSE has a glycoform ratio of $60 \%$ di-glycosylated, $28 \%$ mono-glycosylated and $12 \%$ unglycosylated with bands at 28,22 and 18 $\mathrm{kDa}$, respectively ${ }^{17,18)}$. H type BSE di-glycosylated proteins are detected at $30 \mathrm{kDa}$ followed by the mono-glycosylated at $24 \mathrm{kDa}$ and unglycosylated at $20 \mathrm{kDa}^{3,18)}$. The glycoform ratios for $\mathrm{H}$ type BSE are very similar to classical BSE when using core antibodies for western blot detection. L type BSE has a ratio of $45 \%$ di-glycosylated, 35\% mono-glycosylated and $20 \%$ unglycosylated with molecular weights of 27,21 and $17 \mathrm{kDa}$, respectively ${ }^{2,18)}$. Typing methods based on molecular and biochemical characteristics and combining several of these characteristics produce reliable results ${ }^{19)}$.

BSE surveillance is largely based on rapid test platforms which detect the partially protease resistant prion protein, $\mathrm{PrPSC}^{\mathrm{SC}}$. While this approach worked well for classical BSE, difference in the biochemical properties of $\mathrm{PrP}^{\mathrm{SC}}$ in atypical BSE initially raised concerns. Perhaps the protease digestion conditions optimized for classical BSE would be too aggressive for atypical BSE and result in false negative results or in a decreased sensitivity for the atypical BSE types. Recent studies have shown that the commonly used rapid BSE tests perform well with atypical BSE and that all tests meet the European Food Safety Authority required sensitivity criteria $^{20,21)}$. 


\section{Atypical BSE Transmission}

Different prion disease types have different intra- and inter-species transmissibility. These characteristic are useful to define and identify unique strains and to determine the risk of infection. Classical BSE is efficiently transmitted to $50 \%$ of animals challenged orally with as little as $0.15 \mathrm{~g}$ of high titre BSE brain (95\% confidence interval $)^{22)}$. Oral challenges with classical BSE have also been successful to transmit disease to other species including cynamologous macaques ${ }^{23,24)}$, sheep and goats ${ }^{25,26)}$. Proof of oral transmissibility of classical BSE has resulted in ruminant to ruminant feed bans and specified risk material removal to prevent intra- and interspecies transmission by consumption of contaminated food or feed. Specified risk materials are tissues or regions in an infected animal containing high levels of $\mathrm{PrP}^{\mathrm{SC}}$ and/or infectivity. In classical BSE, infectivity is the highest in the Peyer's patches of the distal ileum, the retina and the central nervous system ${ }^{27)}$.

Despite the fact that atypical BSE involves a similar misfolding of the same protein as classical BSE, the pathogenic characteristics are quite different. While intra-species transmission of atypical BSE has been successfully achieved via the intra-cranial route ${ }^{28)}$, evidence to support successful oral transmission is lacking. In an ongoing experiment at the CFIA Lethbridge Laboratory, cattle were orally challenged with $100 \mathrm{~g}$ of strong positive classical, $\mathrm{H}$ or L type atypical BSE brain, respectively. While all $\mathrm{C}$ type BSE animals developed clinical disease and were euthanized, most atypical BSE challenged animals are clinically normal at 6 years post exposure. If atypical BSE does transmit with a longer incubation, it would contradict the observations in the intracranial challenge. Cattle challenged intra-cranially with atypical BSE have a documented incubation time of 14-21 months ${ }^{29-31)}$. Intracranial challenge of cattle with classical BSE results in significantly longer incubation with clinical disease starting around 24 months ${ }^{12)}$.

\section{New Atypical BSE Strains?}

With three BSE types already identified and relatively well characterized, the potential of additional types of BSE cannot be excluded. As in atypical BSE, new types could have different characteristics and pose different risks to the health of animals and humans. Several countries have reported low level reactivity in samples submitted for BSE surveillance ${ }^{32-34)}$. There is suggestion that these cases represent a yet to be identified prion disease of cattle ${ }^{32}$, but also proposed alternative explanations ${ }^{33)}$. To definitively determine if these animals are infected with a prion disease that is transmissible, brain homogenates were intra-cranially inoculated into transgenic mice and cattle. These bioassays have concluded and results are to be published soon (Dr. T. Seuberlich, personal communication). In addition, the identification of a different prion strain after several passages of $\mathrm{H}$ type BSE in bovine transgenic mice was recently reported $^{35)}$. Comparable to scrapie, this presents the possible co-existence of strains; the relevance of this finding in a natural setting is yet to be determined.

\section{Conclusion}

The discovery of atypical BSE resulted in new questions and challenges for the scientific, risk assessment and regulatory communities. There are many efforts from scientists all over the world to generate knowledge on atypical BSE to minimize the risks to human and animal health, but the potential threat of new types of BSE necessitates continued research and surveillance testing. By maintaining these programs the expertise, knowledge and skills required to effectively and efficiently deal with the emergence of a new types of BSE will be available should they be needed.

\section{References}

1. Wells GAH, Scott AC, Johnson CT, et al. A novel progressive spongiform encephalopathy in cattle. Vet Rec. 1987; 121: 419-420.; doi: 10.1136/vr.121.18.419. [Medline]

2. Casalone C, Zanusso G, Acutis P, et al. Identification of a second bovine amyloidotic spongiform encephalopathy: molecular similarities with sporadic Creutzfeldt-Jakob disease. Proc Natl Acad Sci USA. 2004; 101: 3065-3070.; doi: 10.1073/ pnas.0305777101. [Medline]

3. Biacabe AG, Laplanche JL, Ryder S, Baron T. Distinct molecular phenotypes in bovine prion diseases. EMBO Rep. 2004; 5: 110-115.; doi: 10.1038/sj.embor.7400054. [Medline]

4. Wells GA, Wilesmith JW, McGill IS. Bovine spongiform encephalopathy: a neuropathological perspective. Brain Pathol. 1991; 1: 69-78. Review. [Medline]

5. Brown P, McShane LM, Zanusso G, Detwile L. On the question of sporadic or atypical bovine spongiform encephalopathy and Creutzfeldt-Jakob disease. Emerg Infect Dis. 2006; 12: 1816-1821. [Medline]

6. Sala C, Morignat E, Oussaïd N, et al. Individual factors associated with L- and H-type Bovine Spongiform encephalopathy in France. BMC Vet Res. 2012; 8: 74.; doi: 10.1186/17466148-8-74. [Medline]

7. Biacabe AG, Morignat E, Vulin J, Calavas D, Baron TG. Atypical bovine spongiform encephalopathies, France, 20012007. Emerg Infect Dis. 2008; 14: 298-300.; doi: 10.3201/ eid1402.071141. [Medline]

8. Baron T, Vulin J, Biacabe AG, et al. Emergence of classical BSE strain properties during serial passages of H-BSE in wild-type mice. PLoS One. 2011; 6: e15839. [Medline] 
9. Torres JM, Andréoletti O, Lacroux C, et al. Classical bovine spongiform encephalopathy by transmission of H-type prion in homologous prion protein context. Emerg Infect Dis. 2011; 17: 1636-1644.; doi: 10.3201/eid1709.101403. [Medline]

10. Nicholson, E.M., B.W. Brunelle, J.A. Richt, M.E. Kehrli, J.J. Greenlee, Identification of a heritable polymorphism in bovine PRNP associated with genetic transmissible spongiform encephalopathy: evidence of heritable BSE. PLoS One, 2008, 13; 3(8):e2912. doi: 10.1371/journal.pone.0002912.

11. Hsiao, K., Z. Meiner, E. Kahana, C. Cass, I. Kahana, D. Avrahami, G. Scarlato, O. Abramsky, S.B. Prusiner, R. Gabizon, Mutation of the prion protein in Libyan Jews with CreutzfeldtJakob disease. N Engl J Med, 1991, 18; 324(16):1091-7.

12. Moore, S.J., M.H. West Greenlee, J.D. Smith, C.E. Vrentas, E.M. Nicholson, J.J. Greenlee, A Comparison of Classical and H-Type Bovine Spongiform Encephalopathy Associated with E211 K Prion Protein Polymorphism in Wild-Type and EK211 Cattle Following Intracranial Inoculation. Front Vet Sci, 2016, 15; 3:78.

13. Prusiner SB. Prions. Proc Natl Acad Sci USA. 1998; 95: 13363-13383.; doi: 10.1073/pnas.95.23.13363. [Medline]

14. Meyer RK, McKinley MP, Bowman KA, Braunfeld MB, Barry RA, Prusiner SB. Separation and properties of cellular and scrapie prion proteins. Proc Natl Acad Sci USA. 1986; 83: 2310-2314.; doi: 10.1073/pnas.83.8.2310. [Medline]

15. Mallucci G, Dickinson A, Linehan J, Klöhn PC, Brandner S, Collinge J. Depleting neuronal PrP in prion infection prevents disease and reverses spongiosis. Science. 2003; 302: 871-874. [Medline]

16. Stack M, Jeffrey M, Gubbins S, et al. Monitoring for bovine spongiform encephalopathy in sheep in Great Britain, 1998-2004. J Gen Virol. 2006; 87: 2099-2107.; doi: 10.1099/ vir.0.81254-0. [Medline]

17. Jacobs JG, Langeveld JP, Biacabe AG, et al. Molecular discrimination of atypical bovine spongiform encephalopathy strains from a geographical region spanning a wide area in Europe. J Clin Microbiol. 2007; 45: 1821-1829. [Medline]

18. Priemer G, Balkema-Buschmann A, Hills B, Groschup MH. Biochemical Characteristics and $\operatorname{PrP}(\mathrm{Sc})$ Distribution Pattern in the Brains of Cattle Experimentally Challenged with Htype and L-type Atypical BSE. PLoS One. 2013; 8: e67599. [Medline]

19. Langeveld JP, Erkens JHF, Rammel I, et al. Four independent molecular prion protein parameters for discriminating new cases of $\mathrm{C}, \mathrm{L}$, and $\mathrm{h}$ bovine spongiform encephalopathy in cattle. J Clin Microbiol. 2011; 49: 3026-3028.; doi: 10.1128/ JCM.01102-11. [Medline]

20. Gray JG, Dudas S, Graham C, Czub S. Performance analysis of rapid diagnostic tests on atypical bovine spongiform encephalopathy. J Vet Diagn Invest. 2012; 24: 976-980. [Medline]

21. Meloni D, Davidse A, Langeveld JPM, et al. EU-approved rapid tests for bovine spongiform encephalopathy detect atypical forms: a study for their sensitivities. PLoS One. 2012; 7: e43133. [Medline]
22. Konold T, Arnold ME, Austin AR, et al. Bovine spongiform encephalopathy: the effect of oral exposure dose on attack rate and incubation period in cattle - an update. BMC Research Notes. 2012; 5: 674.; doi: 10.1186/1756-0500-5-674. [Medline]

23. Holznagel E, Yutzy B, Schulz-Schaeffer W, et al. Foodborne transmission of bovine spongiform encephalopathy to nonhuman primates. Emerg Infect Dis. 2013; 19: 712-720.; doi: 10.1186/1756-0500-5-674. [Medline]

24. Lasmézas CI, Comoy E, Hawkins S, et al. Risk of oral infection with bovine spongiform encephalopathy agent in primates. Lancet. 2005; 365: 781-783. [Medline]

25. Bellworthy SJ, Dexter G, Stack M, et al. Oral transmission of BSE to VRQ/VRQ sheep in an experimental flock. Vet Rec. 2008; 162: 130-131. [Medline]

26. Foster JD, Hope J, Fraser H. Transmission of bovine spongiform encephalopathy to sheep and goats. Vet Rec. 1993; 133: 339-341. [Medline]

27. Espinosa JC, Morales M, Castilla J, Rogers M, Torres JM. Progression of prion infectivity in asymptomatic cattle after oral bovine spongiform encephalopathy challenge. J Gen $\mathrm{Vi}$ rol. 2007; 88: 1379-1383. [Medline]

28. Balkema-Buschmann A, Fast C, Kaatz M, et al. Pathogenesis of classical and atypical BSE in cattle. Prev Vet Med. 2011; 102: 112-117. [Medline]

29. Buschmann, A., A. Gretzschel, A.G. Biacabe, K. Schiebel, C. Corona, C. Hoffmann, M. Eiden, T. Baron, C. Casalone, M.H. Groschup, Atypical BSE in Germany-proof of transmissibility and biochemical characterization. Vet Microbiol, 2006, 117:103-116 (18).

30. Okada H, Iwamaru Y, Imamura M, et al. Experimental Htype bovine spongiform encephalopathy characterized by plaques and glial- and stellate-type prion protein deposits. Vet Res. 2011; 42: 79.; doi: 10.1186/1297-9716-42-79. [Medline]

31. Konold T, Bone GE, Clifford D, et al. Experimental H-type and L-type bovine spongiform encephalopathy in cattle: observation of two clinical syndromes and diagnostic challenges. BMC Vet Res. 2012; 8: 22.; doi:10.1186/1746-6148-8-22. [Medline]

32. Seuberlich T, Gsponer M, Drögemüller C, et al. Novel prion protein in BSE-affected cattle, Switzerland. Emerg Infect Dis. 2012; 18: 158-159.; doi: 10.3201/eid1801.111225. [Medline]

33. Dudas S, James J, Anderson R, Czub S. Exploring the cause of initially reactive bovine brains on rapid tests for BSE. Prion. 2015; 9: 429-443.; doi: 10.1080/19336896.2015.1115945. [Medline]

34. Sarasa, R., D. Becher, J.J. Badiola, M. Monzón, A comparative study of modified confirmatory techniques and additional immuno-based methods for non-conclusive autolytic bovine spongiform encephalopathy cases. BMC Vet Res, 2013, 18; 9:212. doi: 10.1186/1746-6148-9-212.

35. Masujin K, Okada H, Miyazawa K, et al. Emergence of a novel bovine spongiform encephalopathy (BSE) prion from an atypical H-type BSE. Sci Rep. 2016; 6: 22753.; doi: 10.1038/ srep22753. [Medline] 